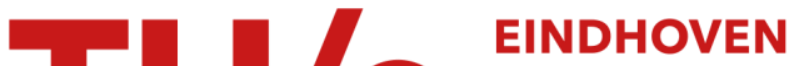 UNIVERSITY OF TECHNOLOGY
}

\section{Monolayer nitrides doped with transition metals as efficient catalysts for water oxidation}

\section{Citation for published version (APA):}

Liang, Q., Brocks, G., Zhang, X., \& Bieberle-Hütter, A. (2019). Monolayer nitrides doped with transition metals as efficient catalysts for water oxidation: the singular role of nickel. Journal of Physical Chemistry C, 123(43), 26289-26298. https://doi.org/10.1021/acs.jpcc.9b06704

\section{Document license:}

TAVERNE

DOI:

10.1021/acs.jpcc.9b06704

Document status and date:

Published: 31/10/2019

\section{Document Version:}

Publisher's PDF, also known as Version of Record (includes final page, issue and volume numbers)

\section{Please check the document version of this publication:}

- A submitted manuscript is the version of the article upon submission and before peer-review. There can be important differences between the submitted version and the official published version of record. People interested in the research are advised to contact the author for the final version of the publication, or visit the $\mathrm{DOI}$ to the publisher's website.

- The final author version and the galley proof are versions of the publication after peer review.

- The final published version features the final layout of the paper including the volume, issue and page numbers.

Link to publication

\section{General rights}

Copyright and moral rights for the publications made accessible in the public portal are retained by the authors and/or other copyright owners and it is a condition of accessing publications that users recognise and abide by the legal requirements associated with these rights.

- Users may download and print one copy of any publication from the public portal for the purpose of private study or research.

- You may not further distribute the material or use it for any profit-making activity or commercial gain

- You may freely distribute the URL identifying the publication in the public portal.

If the publication is distributed under the terms of Article 25fa of the Dutch Copyright Act, indicated by the "Taverne" license above, please follow below link for the End User Agreement:

www.tue.nl/taverne

Take down policy

If you believe that this document breaches copyright please contact us at:

openaccess@tue.nl

providing details and we will investigate your claim. 


\title{
Monolayer Nitrides Doped with Transition Metals as Efficient Catalysts for Water Oxidation: The Singular Role of Nickel
}

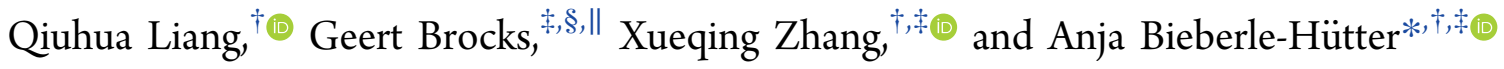

${ }^{\dagger}$ Electrochemical Materials and Interfaces (EMI), Dutch Institute for Fundamental Energy Research (DIFFER), De Zaale 20, 5612 AJ Eindhoven, The Netherlands

${ }^{\ddagger}$ Center for Computational Energy Research (CCER), P.O. Box 513, 5600 MB Eindhoven, The Netherlands

${ }^{\S}$ Department of Applied Physics, Eindhoven University of Technology, P.O. Box 513, 5600 MB Eindhoven, The Netherlands

"Computational Materials Science, Faculty of Science and Technology and MESA+ Institute for Nanotechnology, University of Twente, P.O. Box 217, 7500 AE Enschede, The Netherlands

Supporting Information
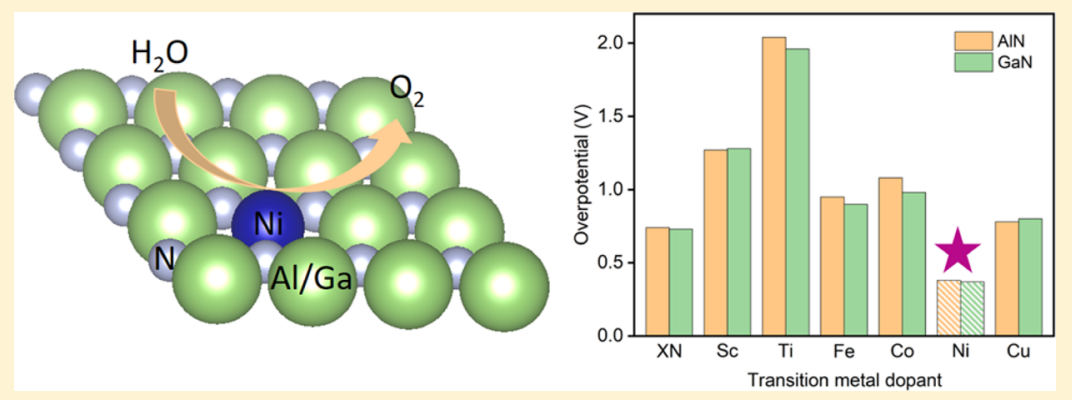

ABSTRACT: Exploration of precious-metal-free catalysts for water splitting is of great importance in developing renewable energy conversion and storage technologies. In this paper, on the basis of density functional theory calculations, we reveal the link between the oxygen evolution reaction (OER) activities and the electronic properties of pure and first-row transition-metal (TM)-doped AlN and GaN two-dimensional monolayers. We find that Ni-doped layers are singularly appealing because they lead to a low overpotential $(0.4 \mathrm{~V})$. Early TM dopants are not suited for the OER because they bind the intermediate species $\mathrm{OH}$ or $\mathrm{O}$ too strongly, which leads to very large overpotentials, or no OER activity at all. The late TM dopants $\mathrm{Cu}$ and $\mathrm{Zn}$ show less or no OER activity as they bind the intermediate species too weakly. Although in many cases the overpotential can be traced back to an $\mathrm{OOH}$ intermediate species being adsorbed too weakly compared to an $\mathrm{OH}$ species, the Ni dopant breaks this rule by stabilizing the $\mathrm{OOH}$ adsorbant. The stabilization can be correlated with a switch from a high-spin to a low-spin state of the dopant atom. This ability to change spin states offers an exciting ingredient for the design of OER catalysts.

\section{INTRODUCTION}

The global greenhouse gas emission and environmental pollution problems require the development of renewable and green energy systems. Electrochemical and photoelectrochemical splitting of water into hydrogen and oxygen present promising approaches to a green and renewable energy conversion and storage technology. ${ }^{1-3}$ Water splitting comprises two half reactions: the cathodic hydrogen evolution reaction and the anodic oxygen evolution reaction (OER). The OER is considered to be the main bottleneck because the reaction requires a high overpotential, which limits the efficiency of the energy conversion. ${ }^{4,5}$ Until now, the most effective electrocatalysts known for the OER are oxides of platinum group transition metals (TMs) such as Ir or Ru., Such electrocatalysts cannot be used in large-scale applications, however, as these TMs are scarce and costly. Over the last few decades, oxides of earth-abundant TMs have also been widely studied as alternatives, such as $\mathrm{Fe}_{2} \mathrm{O}_{3},{ }^{8-11} \mathrm{TiO}_{2},{ }^{12,13} \mathrm{WO}_{3}{ }^{14,15}$ $\mathrm{Co}_{3} \mathrm{O}_{4},{ }^{16,17}$ and $\mathrm{MnO}_{2} \cdot{ }^{18,19}$ Although they are cheap and have a high chemical stability, these TM oxides suffer from high OER overpotentials and low catalytic activities. ${ }^{20-22}$ In addition, as the conductivity of such materials is low, transport of charge carriers becomes a problem. In other words, there is plenty of room for improvement of platinum-group-free TM compounds for OER (photo)electrocatalysis.

It is well known that reducing sizes to the nanometer regime can alter and improve the catalytic properties of materials. Size reduction is recognized as an effective path to improve the electrochemical performance for water splitting. ${ }^{23,24}$ Twodimensional (2D) materials are special, as they naturally come with a reduction of size in one dimension, which facilitates charge transport across the material. At the same time, 2D materials maintain a high surface area, which is important as OER activity critically depends on the number of active surface

Received: July 15, 2019

Revised: September 20, 2019

Published: October 4, 2019 
sites. Since the discovery of the prototype $2 \mathrm{D}$ material graphene, ${ }^{25}$ several $2 \mathrm{D}$ materials have been studied regarding OER activity ${ }^{2,23,26}$ Among these is TM and nitrogen co-doped graphene, where in computational studies, it is claimed that the OER electrocatalytic activity can be comparable to that of platinum group TM oxides. ${ }^{27-29}$ Similarly, the TM-doped 2D materials $\mathrm{C}_{2} \mathrm{~N}$ and $\mathrm{g}-\mathrm{C}_{3} \mathrm{~N}_{4}$ have been proposed as efficient OER catalysts. ${ }^{30,31}$ However, in all of these graphene-like $\mathrm{C}_{x} \mathrm{~N}_{y}$ materials, the TM and nitrogen dopant atoms need to be in specific (e.g., porphyrin-like) configurations to express their catalytic activity, and it is difficult to foresee how these can be synthesized controllably on a large scale.

In this paper, we suggest an alternative approach, starting from the graphene-like nitrides AlN and GaN. These 2D materials have been studied computationally ${ }^{32-34}$ and realized experimentally in recent years. $2 \mathrm{D}$ AlN has been grown on $\mathrm{Ag}(111),{ }^{35}$ and $2 \mathrm{D} \mathrm{GaN}$ has been synthesized using graphene encapsulation. ${ }^{36} \mathrm{AlN}$ - and GaN-based heterostructures have been investigated computationally as potential candidates for water splitting. ${ }^{37-39}$ It is unclear whether such TM-free compounds can show sufficient catalytic activity. However, just like in their three-dimensional counterparts, ${ }^{40-42}$ it should be possible to introduce $\mathrm{TM}$ atoms in $2 \mathrm{D}$ group III-V monolayer materials by substitutional doping, that is, TM atoms replacing the $\mathrm{Ga}$ or $\mathrm{Al}$ cations in the lattice. First-row TM-doped systems have been widely studied as OER catalysts, and the activity of the TM dopant depends on the systems, in particular, on the electronic configuration of the dopant atom, and on the interaction of the dopant atom with the surrounding lattice. In different systems, the TMs show different OER activity. ${ }^{43-47}$ Such substitutional doping should be easier to achieve than the special TM configurations required for the graphene-like $\mathrm{C}_{x} \mathrm{~N}_{y}$ compounds, for instance. In this paper, we have carried out a systematic study of the catalytic activity on the OER of first-row TM-doped monolayers of AlN and GaN.

\section{THEORETICAL METHODS}

All calculations are performed within density functional theory (DFT), using the projector-augmented wave approach, as implemented in the Vienna $\mathrm{Ab}$ initio Simulation Package (VASP). ${ }^{48-50}$ The electronic exchange-correlation energy is treated within the generalized gradient approximation (GGA) as parameterized by Perdew-Burke-Ernzerhof. ${ }^{51}$ To test the stability of the spin states found for the (adsorbed species on the) TM-doped AlN and GaN, we apply the GGA + U method, where the on-site electron-electron Coulomb interaction $U$ is treated within the Dudarev et al. approach. ${ }^{52}$ This is discussed in the Supporting Information.

We construct a $4 \times 4$ in-plane supercell of $\mathrm{XN}(\mathrm{X}=\mathrm{Al}$ or $\mathrm{Ga}$ ) in a planar honeycomb lattice, see Figure 1a. To mimic $\mathrm{TM}$ doping, one $\mathrm{Ga}$ or $\mathrm{Al}$ atom in this supercell is replaced by a TM atom. The intermediate species active in the OER are then absorbed at this TM site. In the direction perpendicular to the $\mathrm{XN}$ plane, the $\mathrm{XN}$ layers are separated by a vacuum spacing of $15 \AA$ to prevent the interaction between periodical images, see Figure 1b, where we also use a dipole correction. ${ }^{53}$ All atoms in the supercell are relaxed until the maximum force on each atom is less than $0.02 \mathrm{eV} / \AA$, and the energy convergence criterion is set to $1 \times 10^{-4} \mathrm{eV}$.

A plane wave basis with a kinetic energy cutoff of $500 \mathrm{eV}$ and a Monkhorst-Pack ${ }^{54}$ grid of $4 \times 4 \times 1 k$-points are used for the geometry optimization. A finer $10 \times 10 \times 1 k$-point

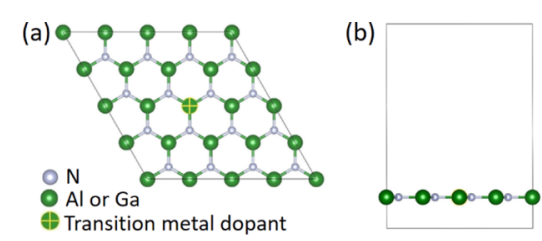

(c)

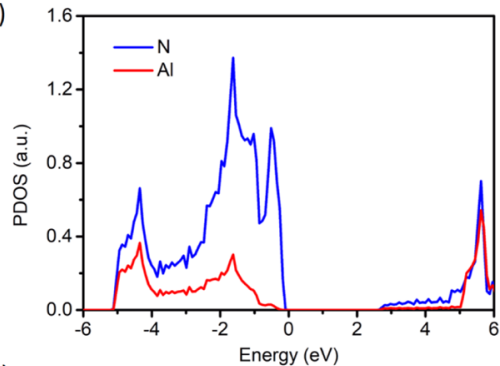

(d)

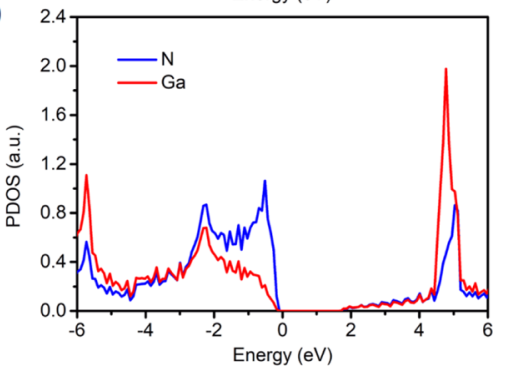

Figure 1. Top (a) and side (b) views of TM-doped hexagonal monolayer nitrides $\mathrm{XN}$ in a $4 \times 4$ supercell $(\mathrm{X}=\mathrm{Al}$ and $\mathrm{Ga})$; PDOS of (c) AlN and (d) GaN monolayers. The top of the valence band is set to zero energy.

mesh is used to calculate the density of states (DOS). In order to describe possible van der Waals interactions between adsorbants and substrate, Grimme's semiempirical DFT-D3 scheme of dispersion correction is used. ${ }^{55}$ In all calculations, we apply spin polarization.

As a test, we analyze the electronic structure of pristine planar AlN and GaN monolayers. The calculated projected densities of states (PDOS) are shown in Figure 1c,d. Both AlN and $\mathrm{GaN}$ are large band gap semiconductors, with DFT band gaps of 2.96 and $1.78 \mathrm{eV}$, respectively, which agree with previous studies. ${ }^{34,37}$ The top of the valence band is dominated by contributions from nitrogen atoms, while the bottom of the conduction band has a mixed cation ( $\mathrm{Al}$ or $\mathrm{Ga}$ )-anion character.

In calculating the total energies of molecules and adsorbed species, we correct for the zero-point energies, obtained from the calculated frequencies $\left(\nu_{i}\right)$ of all vibrations of the atoms in the supercell

$$
\mathrm{ZPE}=\sum_{i} \frac{1}{2} h \nu_{i}
$$

where $h$ is Planck's constant. The vibrational contribution to the entropy $S$ of molecules and adsorbed species can be calculated from these frequencies as ${ }^{56}$

$$
S=k_{\mathrm{B}} \sum_{i}\left[\frac{h \nu_{i}}{k_{\mathrm{B}} T\left(\mathrm{e}^{h \nu_{i} / k_{\mathrm{B}} T}-1\right)}-\ln \left(1-\mathrm{e}^{-h \nu_{i} / k_{\mathrm{B}} T}\right)\right]
$$

with $k_{\mathrm{B}}$ the Boltzmann constant and $T$ the temperature. ${ }^{57}$ In this paper, we set $T=300 \mathrm{~K}$. We used gas-phase $\mathrm{H}_{2} \mathrm{O}$ at 0.035 bar as the reference state because at this pressure, gas-phase $\mathrm{H}_{2} \mathrm{O}$ is in equilibrium with liquid water at $300 \mathrm{~K}^{58}$ Entropies 

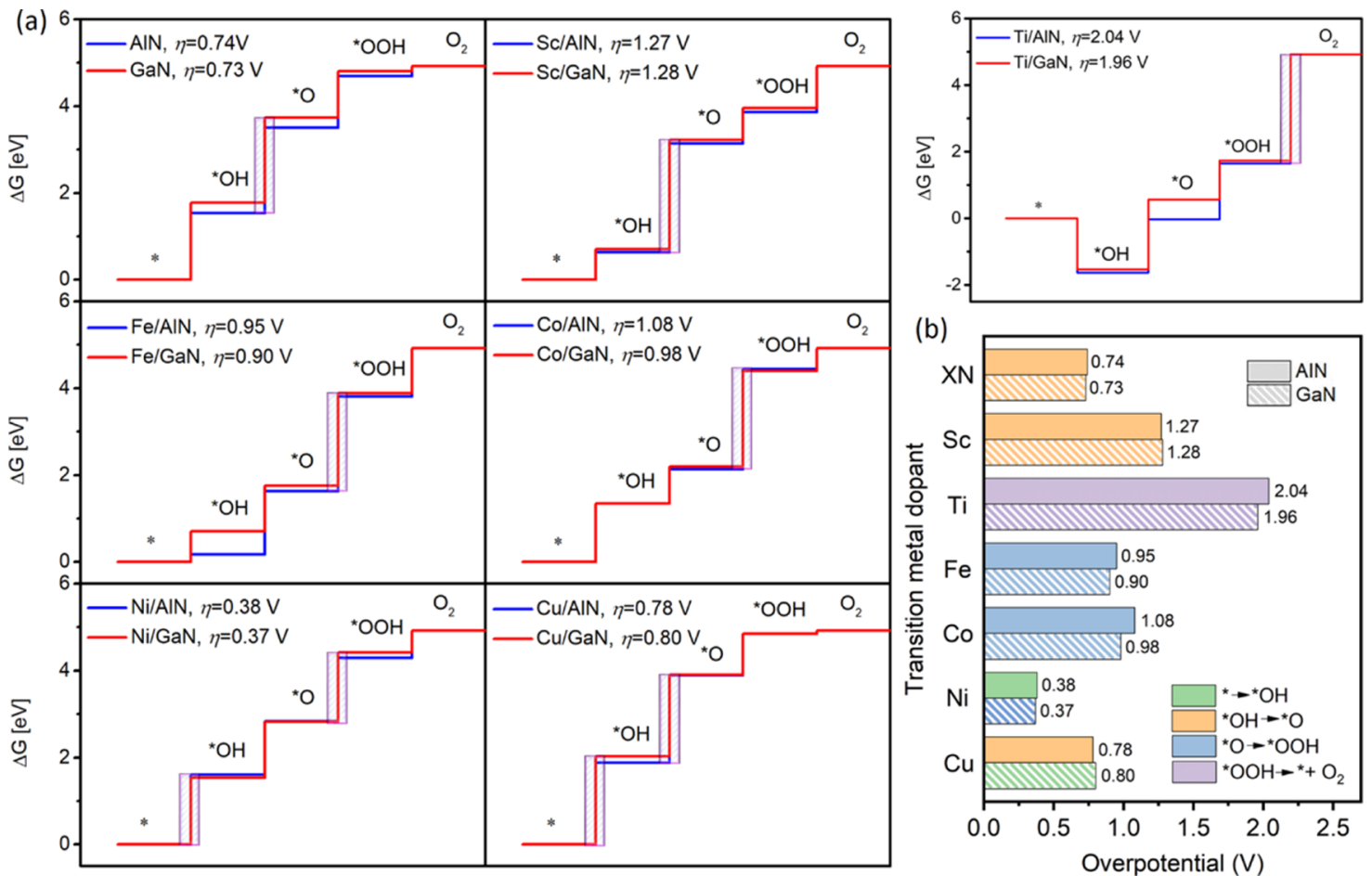

Figure 2. (a) Calculated Gibbs free energy diagrams of pristine and TM-doped AlN and GaN systems. The purple-shaded fields indicate the overpotential-determining reaction steps. The values of the overpotential are given in the legends. (b) Summary plot of the overpotential for the different TM dopants. The overpotential-determining reaction steps are represented by different colors.

of the gases $\mathrm{H}_{2}, \mathrm{O}_{2}$, and $\mathrm{H}_{2} \mathrm{O}$ are taken from the ref 58 (see Table S1). In the solid state, volume changes are typically very small, and the small difference between enthalpy and energy is normally neglected. ${ }^{46}$ We have refrained from modeling solvation effects.

\section{RESULTS AND DISCUSSION}

Reaction Energies and Overpotentials. In an acidic environment, the OER can be expressed as

$$
2 \mathrm{H}_{2} \mathrm{O} \rightarrow \mathrm{O}_{2}+4 \mathrm{e}^{-}+4 \mathrm{H}^{+}
$$

We follow the reaction mechanism established by Rossmeisl et al., ${ }^{59}$ where the OER proceeds in four sequential steps at the same reaction site, each step involving a single electron and proton

$$
\begin{aligned}
& \mathrm{H}_{2} \mathrm{O}(\mathrm{l})+* \rightarrow * \mathrm{OH}+\mathrm{H}^{+}+\mathrm{e}^{-} \\
& * \mathrm{OH} \rightarrow * \mathrm{O}+\mathrm{H}^{+}+\mathrm{e}^{-} \\
& \mathrm{H}_{2} \mathrm{O}(\mathrm{l})+* \mathrm{O} \rightarrow{ }^{*} \mathrm{OOH}+\mathrm{H}^{+}+\mathrm{e}^{-} \\
& * \mathrm{OOH} \rightarrow *+\mathrm{O}_{2}(\mathrm{~g})+\mathrm{H}^{+}+\mathrm{e}^{-}
\end{aligned}
$$

Here, * represents the surface; (l) and (g) refer to the liquid and gas phases, respectively; and $* \mathrm{OH}, * \mathrm{O}$, and $* \mathrm{OOH}$ represent the species adsorbed on the surface. Assuming the standard hydrogen electrode as the reference electrode, we have the equilibrium

$$
\frac{1}{2} \mathrm{H}_{2} \leftrightarrow \mathrm{e}^{-}+\mathrm{H}^{+}
$$

at $T=300 \mathrm{~K}, \mathrm{pH}=0$, and a hydrogen gas pressure of 1 bar. Assuming this equilibrium, we may then replace the protons plus electrons in reactions $3-7$ by hydrogen gas under these conditions in calculations of the reaction-free energies. Water molecules adsorbed on the surface are in equilibrium with liquid water, and oxygen molecules adsorbed on the surface are in equilibrium with oxygen gas under standard conditions. The Gibbs free energies of $\mathrm{H}_{2} \mathrm{O}$ and $\mathrm{O}_{2}$ adsorption are then equal to that of a water molecule in the liquid and an $\mathrm{O}_{2}$ molecule in the gas, respectively. Note that for microkinetic modeling, one would need to broaden this scope. ${ }^{60}$ The Gibbs free energy of reaction 3 is then $4.92 \mathrm{eV}$, that is, twice the standard formation energy $\Delta G_{\mathrm{H}_{2} \mathrm{O}}$ of a $\mathrm{H}_{2} \mathrm{O}$ molecule from $\mathrm{H}_{2}$ and $1 / 2 \mathrm{O}_{2}$. Assuming that each of the four steps $4-7$ has the same Gibbs free energy, $\Delta G_{0}$, then gives

$$
\Delta G_{0}=\frac{1}{2} \Delta G_{\mathrm{H}_{2} \mathrm{O}}=1.23 \mathrm{eV}
$$

which is the minimum potential required for this reaction to proceed. In reality, the four steps will not have the same Gibbs free energy, which then leads to an overpotential.

For each of these four steps, we calculate the reaction Gibbs free energy as

$$
\begin{aligned}
\Delta G_{1}= & E(* \mathrm{OH})-E(*)-E_{\mathrm{H}_{2} \mathrm{O}}+\frac{1}{2} E_{\mathrm{H}_{2}} \\
& +(\Delta \mathrm{ZPE}-T \Delta S)_{1} \\
\Delta G_{2}= & E(* \mathrm{O})-E(* \mathrm{OH})+\frac{1}{2} E_{\mathrm{H}_{2}}+(\Delta \mathrm{ZPE}-T \Delta S)_{2}
\end{aligned}
$$

$$
\begin{aligned}
\Delta G_{3}= & E(* \mathrm{OOH})-E(* \mathrm{O})-E_{\mathrm{H}_{2} \mathrm{O}}+\frac{1}{2} E_{\mathrm{H}_{2}} \\
& +(\Delta \mathrm{ZPE}-T \Delta S)_{3}
\end{aligned}
$$




$$
\begin{aligned}
\Delta G_{4}= & E(*)-E(* \mathrm{OOH})+E_{\mathrm{O}_{2}}+\frac{1}{2} E_{\mathrm{H}_{2}} \\
& +(\Delta \mathrm{ZPE}-T \Delta S)_{4}
\end{aligned}
$$

$\Delta G_{i}$, with $i=1-4$, are the Gibbs free energies associated with the four reactions of eqs $4-7 . E(*), E(* \mathrm{OH}), E(* \mathrm{O})$, and $E(* \mathrm{OOH})$ are the calculated total energies of a clean surface and surfaces with a single adsorbed $\mathrm{OH}, \mathrm{O}$, and $\mathrm{OOH}$ species, respectively. $E_{\mathrm{H}_{2} \mathrm{O}}, E_{\mathrm{H}_{2}}$ and $E_{\mathrm{O}_{2}}$ are the calculated total energies of a $\mathrm{H}_{2} \mathrm{O}, \mathrm{H}_{2}$, and $\mathrm{O}_{2}$ molecule. $\Delta \mathrm{ZPE}$ and $T \Delta S$ are the changes in zero-point energies and entropy contributions related to the different adsorbed species, calculated as discussed in the "Theoretical Methods" section.

The overpotential, $\eta$, which is used as the quantity determining the electrochemical activity, is defined as

$$
\eta=\max \left[\eta_{1}, \eta_{2}, \eta_{3}, \eta_{4}\right]
$$

with $\eta_{i}=\left(\Delta G_{i}-\Delta G_{0}\right) / e$ for $i=1-4$. Note that $\eta \geq 0$, as the sum of reactions $4-7$ gives reaction 3

$$
\Delta G_{1}+\Delta G_{2}+\Delta G_{3}+\Delta G_{4}=2 \Delta G_{\mathrm{H}_{2} \mathrm{O}}=4 \Delta G_{0}
$$

Hence, if the Gibbs free energy of one of the reaction steps is smaller than $\Delta G_{0}$, then the Gibbs free energy of one or more of the other reaction steps has to be larger than $\Delta G_{0}$.

We calculate the Gibbs free energies $10-13$ of the four reactions 4-7 for pristine $\mathrm{XN}$ and $\mathrm{TM}$-doped $\mathrm{XN}, \mathrm{X}=\mathrm{Al}$ and $\mathrm{Ga}$, and $\mathrm{TM}$ from the $3 \mathrm{~d}$ series ( $\mathrm{Sc}$ to $\mathrm{Zn}$ in the periodic table). The structures of $* \mathrm{OH}, * \mathrm{O}$, and $* \mathrm{OOH}$ for the different (doped) surfaces are shown in Figure S1. For pristine $\mathrm{XN}, \mathrm{OH}$ and $\mathrm{OOH}$ adsorb on top of an $\mathrm{X}$ cation, whereas $\mathrm{O}$ adsorbs at a hollow site. For TM-doped XN, all stable species adsorb in a position on top of the TM atom. The exception is $\mathrm{Zn}$, which shows no activity toward $\mathrm{OH}$ adsorption; instead, $\mathrm{OH}$ binds to an $\mathrm{X}$ cation. As the $\mathrm{Zn}$ dopant is thus totally inert, we omit it from most of the discussion below. We find that the $\mathrm{OOH}$ species cannot be stably adsorbed on $\mathrm{V}, \mathrm{Cr}$, and $\mathrm{Mn}$ dopant atoms, which means that the two reactions 6 and 7 cannot proceed for these systems. Instead, the $\mathrm{OOH}$ species spontaneously dissociates into an $\mathrm{O}$ species adsorbed on top of the TM atom and a separate $\mathrm{OH}$ species adsorbed on a bridge site between the two $\mathrm{X}$ cations.

Disregarding these TM dopants, Figure 2a shows the Gibbs free energies $10-13$ of the four reaction steps, calculated for the pristine $\mathrm{XN}$ monolayers, and the TM-doped $\mathrm{XN}$ for the $3 \mathrm{~d}$ $\mathrm{TM}$ atoms $\mathrm{Sc}, \mathrm{Ti}, \mathrm{Fe}, \mathrm{Co}, \mathrm{Ni}$, and $\mathrm{Cu}$. The overpotential and the overpotential-determining reaction steps are presented in Figure 2b. All data to these plots are listed in Table S2. Note that the difference between the initial plateau, marked $*$, and the final plateau, marked $\mathrm{O}_{2}$, is fixed to $4.92 \mathrm{eV}$, because of the sum rule of eq 15 . The $\Delta G$ staircases can be qualitatively very different for the different TM dopants, and the overpotentialdetermining reaction step varies. It is then not surprising that large differences in the overpotential are found among these systems.

Pristine AlN and GaN monolayers show similar overpotentials of 0.74 and $0.73 \mathrm{~V}$, respectively. The early TM dopants Sc and Ti lead to considerably higher overpotentials, the late TM dopants $\mathrm{Fe}$ and $\mathrm{Co}$ give moderately higher overpotentials, and $\mathrm{Cu}$ gives a comparable overpotential to the pristine layers. Most interesting is the late TM dopant $\mathrm{Ni}$, which gives a significantly lower overpotential. The low overpotential for the $\mathrm{Ni}$-doped $\mathrm{AlN}$ and GaN layers is in fact comparable to those of the best platinum group TM oxides, for example, $\mathrm{RuO}_{2}$ with an overpotential of $0.37 \mathrm{~V}$ and $\mathrm{IrO}_{2}$ with $0.56 \mathrm{~V}^{59}$ The latter results have been obtained with slightly different computational methods and settings. However, we can benchmark our method from calculations on hematite. ${ }^{8,9}$ For instance, the hematite (110) surface with an oxygen vacancy concentration of 1.26 vacancies $/ \mathrm{nm}^{2}$ leads to an overpotential of $0.47 \mathrm{~V},{ }^{9}$ which is in agreement with other computational studies, as well as with experimental data. ${ }^{46,61}$

Binding Energies of Adsorbed Species. To analyze the trends in the calculated overpotentials, it is helpful to consider the adsorption energies of the different species. The Gibbs free energies of adsorption $\Delta G_{\mathrm{ADS}}$, where $\mathrm{ADS}$ is the adsorbed species $* \mathrm{OH}, * \mathrm{O}$, or $* \mathrm{OOH}$, relative to the clean surface $(*)$ and to $\mathrm{H}_{2}$ and $\mathrm{H}_{2} \mathrm{O}$, can be straightforwardly obtained from the Gibbs free energies of reactions 10-13

$$
\begin{aligned}
\Delta G_{* \mathrm{OH}}= & \Delta G_{1} \\
= & E(* \mathrm{OH})-E(*)-E_{\mathrm{H}_{2} \mathrm{O}}+\frac{1}{2} E_{\mathrm{H}_{2}} \\
& +(\Delta \mathrm{ZPE}-T \Delta S)_{1} \\
\Delta G_{* \mathrm{O}}= & \Delta G_{1}+\Delta G_{2} \\
= & E(* \mathrm{O})-E(*)-E_{\mathrm{H}_{2} \mathrm{O}}+E_{\mathrm{H}_{2}} \\
& +(\Delta \mathrm{ZPE}-T \Delta S)_{1+2} \\
\Delta G_{* \mathrm{OOH}} & \Delta G_{1}+\Delta G_{2}+\Delta G_{3} \\
= & E(* \mathrm{OOH})-E(*)-2 E_{\mathrm{H}_{2} \mathrm{O}}+\frac{3}{2} E_{\mathrm{H}_{2}} \\
& +(\Delta \mathrm{ZPE}-T \Delta S)_{1+2+3}
\end{aligned}
$$

Note that $\Delta G_{* \mathrm{OOH}}$ can only be calculated for those cases where the $\mathrm{OOH}$ species can be adsorbed stably. The Gibbs free energies $\Delta G_{*_{\mathrm{OH}}}, \Delta G_{*_{\mathrm{O}} \mathrm{O}}$, and $\Delta G_{*_{\mathrm{OOH}}}$ for the pristine and the TM-doped AlN and GaN layers are shown in Figure 3. The lower the Gibbs free energy, the stronger the binding of the molecular species to the active site in the monolayer.

Starting with the $\mathrm{OH}$ adsorption (black squares in Figure 3), it is found that $\Delta G_{* \mathrm{OH}}$ varies considerably with the TM dopant, where a similar behavior is found for TM-doped AlN (Figure 3a) and GaN (Figure 3b). Along the TM series, $\Delta G_{* \mathrm{OH}}$ decreases strongly from $\mathrm{Sc}$ to $\mathrm{Ti}$ and increases more gradually from $\mathrm{Ti}$ to $\mathrm{Cu}$, where the minimum value is at $\mathrm{Ti}$. Such an increase for late TMs, signaling a decrease in bonding with the adsorbed $\mathrm{OH}$, is consistent with the results found in previous studies. ${ }^{28} \Delta G_{*} \mathrm{OH}$ is actually negative from $\mathrm{Ti}$ to $\mathrm{Cr}$, indicating that $\mathrm{OH}$ is strongly bonded to the TM dopant in these systems, and even for $\mathrm{Sc}, \mathrm{Mn}$, and $\mathrm{Fe}$, it is barely positive. This is unfavorable for obtaining a low overpotential.

As discussed in the previous section, the ideal Gibbs free energies of reactions $10-13$ are $\Delta G_{0}(1.23 \mathrm{eV})$, eq 9 , as this results in a zero overpotential. The deviation of $* \mathrm{OH}$ from ideal adsorption can then be defined as

$$
\Delta \Delta G_{* \mathrm{OH}}=\Delta G_{* \mathrm{OH}}-\Delta G_{0}=\Delta G_{1}-\Delta G_{0}
$$

Hence, for cases with negative and barely positive $\Delta G_{* \mathrm{OH}}$, $\Delta \Delta G_{* \mathrm{OH}}$ is substantially negative. Because of the sum rule that exists for the reaction Gibbs free energies, eq $15,\left|\Delta \Delta G_{*{ }_{* H}}\right|$ has to be added to the sum of the remaining three reaction steps, $11-13$, which can lead to a substantial overpotential. This is 


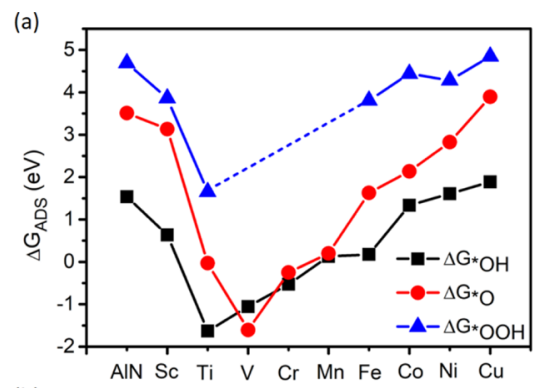

(b)

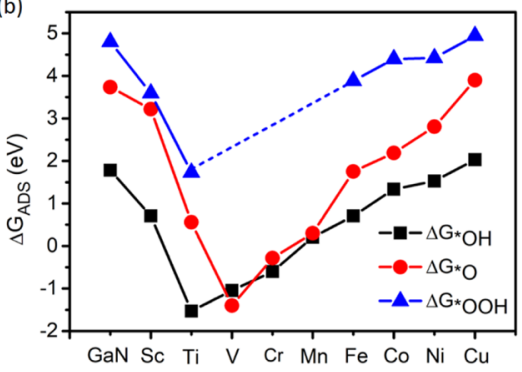

Figure 3. Gibbs free energies of adsorption, $\Delta G_{\mathrm{ADS}}$, for $\mathrm{ADS}=* \mathrm{OH}$ (black squares), *O (red circles), and $* \mathrm{OOH}$ (blue triangles) on TMdoped (a) AlN and (b) GaN monolayers, according to eqs 16-18; the lines are to guide the eye.

clearly visible in the $\Delta G$ staircase for Ti in Figure 2, where the first step $\Delta G_{1}$ goes down. This step in the wrong direction has to be compensated by the remaining three steps, which results in at least one step being significantly larger than $\Delta G_{0}$, and a large overpotential (in this case $\eta=\left(\Delta G_{4}-\Delta G_{0}\right) / e \approx 2 \mathrm{~V}$, eq 16). In conclusion, a strongly negative $\Delta \Delta G_{* \mathrm{OH}}$ (strong bonding of the $\mathrm{OH}$ species) is detrimental for a low overpotential. This would imply that all early TM dopants from $\mathrm{Sc}$ to $\mathrm{Fe}$ are less suitable for the OER.

The $\Delta G_{*_{\mathrm{O}}}$ curve in Figure 3 shows qualitatively a similar behavior as the $\Delta G_{*_{\mathrm{OH}}}$ curve. Along the TM series, $\Delta G_{*_{\mathrm{O}}}$ decreases strongly from Sc to $\mathrm{V}$ and increases more gradually from $\mathrm{V}$ to $\mathrm{Cu}$. Compared to the $\Delta G_{* \mathrm{OH}}$ curve, the minimum is displaced from $\mathrm{Ti}$ to $\mathrm{V}$.

The $\Delta G_{* \mathrm{OOH}}$ curve is remarkably similar in shape to the $\Delta G_{* \mathrm{OH}}$ curve. In fact, subtracting a fixed number from all $\Delta G_{* \mathrm{OOH}}$ values brings the $\Delta G_{*_{\mathrm{OOOH}}}$ and $\Delta G_{* \mathrm{OH}}$ curves close. We will discuss this point in more detail below. Meanwhile, it can be deduced from these curves that the $\mathrm{OOH}$ species cannot be adsorbed in a thermodynamically stable way on the TM dopants V, Cr, and Mn. The Gibbs free energy of dissociation of $* \mathrm{OOH}$ into $* \mathrm{O}$ and $* \mathrm{OH}$, all adsorbed on a dopant atom, is given by

$$
\begin{aligned}
& \Delta G_{* \mathrm{OOH}}^{\mathrm{dis}}=\Delta G_{* \mathrm{OOH}}-\Delta G_{* \mathrm{OH}}-\Delta G_{* \mathrm{O}}=\Delta G_{3}-\Delta G_{1} \\
& \quad=E(* \mathrm{OOH})+E(*)-E(* \mathrm{O})-E(* \mathrm{OH}) \\
& \quad+(\Delta \mathrm{ZPE}-T \Delta S)_{3-1}
\end{aligned}
$$

If $\Delta G_{* \mathrm{OOH}}^{\text {dis }}<0$, then an adsorbed $\mathrm{OOH}$ species is thermodynamically stable against dissociation into adsorbed $\mathrm{O}$ and $\mathrm{OH}$ species. For all TM dopants where $\Delta G_{* \mathrm{OOH}}$ can be calculated, we find from Figure 3 that $2.7 \mathrm{eV}<\Delta G_{* \mathrm{OOH}}-$ $\Delta G_{* \mathrm{OH}}<3.6 \mathrm{eV}$. Taking the lower limit of this, it means that $\Delta G_{*_{\mathrm{O}}}>2.7 \mathrm{eV}$ for the result of eq 20 to be negative, signaling a thermodynamically stable $* \mathrm{OOH}$ species. This is clearly not the case for the V, Cr, and Mn dopants in Figure 3. Moreover, calculation of $\Delta G_{* \mathrm{OOH}}^{\mathrm{dis}}$, eq 20 , according to the numbers given in Figure 3 and Table S2, shows that the $\mathrm{Ti}, \mathrm{Fe}$, and Co dopants also do not yield a stable $* \mathrm{OOH}$. For all these TM dopants, $* \mathrm{O}$ is too stable, and ${ }^{*} \mathrm{OOH}$ may dissociate into $* \mathrm{OH}$ and $* \mathrm{O}$, all adsorbed on top of a dopant atom.

One could argue that $* \mathrm{OOH}$ might be metastable for the $\mathrm{Ti}$, $\mathrm{Fe}$, and $\mathrm{Co}$ dopants because the TM dopant atoms are sufficiently far apart for a dissociation into $* \mathrm{O}$ and $* \mathrm{OH}$ to occur. One may envision another dissociation reaction with the $\mathrm{O}$ species adsorbed on a TM dopant atom, and the $\mathrm{OH}$ adsorbed on the adjacent dopant-free part of the surface, see Figure S1d-f. The Gibbs free energy of dissociation, $\Delta G_{* \mathrm{OOH}}^{\text {dis }}$, of that reaction can be estimated from eq 20 using $\Delta G_{* \mathrm{OH}}=$ $\Delta G_{1}$ of the pristine AlN or GaN, see Table S2. However, even
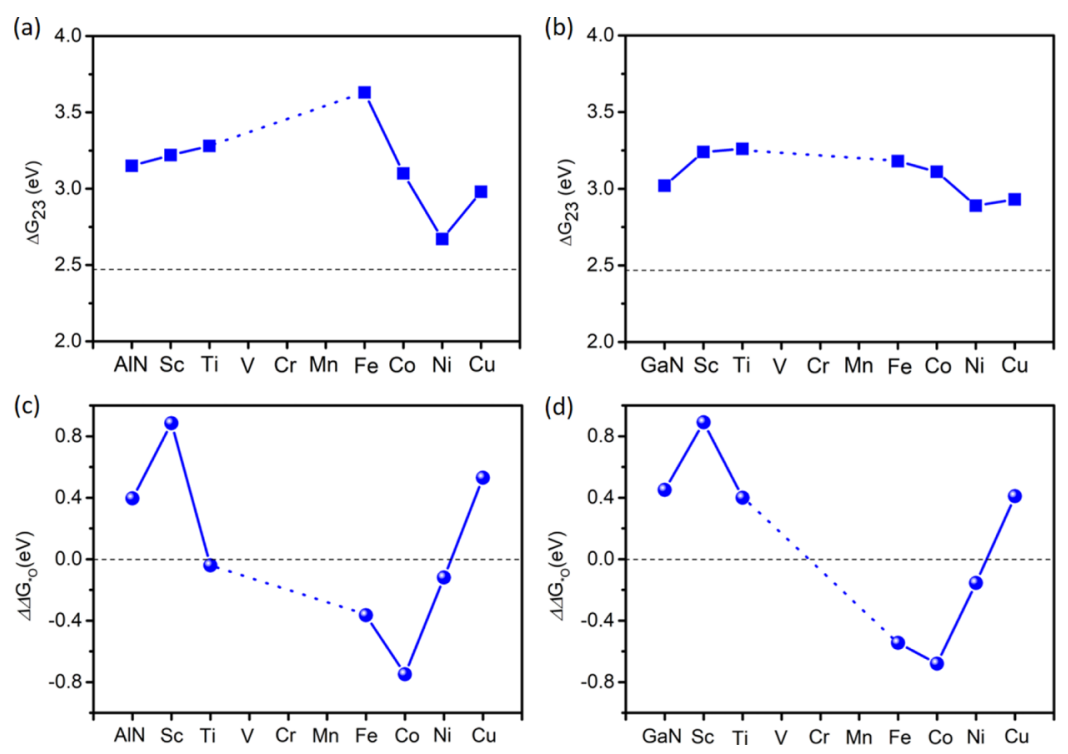

Figure 4. Gibbs free energy difference, $\Delta G_{23}$, on TM-doped (a) AlN and (b) GaN according to eq 21, the dashed horizontal lines indicate the ideal value $2 G_{0}=2.46 \mathrm{eV}$. The Gibbs free energy difference $\Delta \Delta G_{*_{\mathrm{O}}}$ on TM-doped (c) AlN and (d) GaN according to eq 23, the dashed horizontal lines indicate the optimal value of $0 \mathrm{eV}$. The lines are to guide the eye. 
in that case, we find $\Delta G_{* \mathrm{OOH}}^{\text {dis }}>0$ for the $\mathrm{Ti}, \mathrm{Fe}$, and Co dopants, indicating that $* \mathrm{OOH}$ is thermodynamically unstable for these dopant atoms. Nevertheless, in our structural optimization, we do find $* \mathrm{OOH}$ structures that form local minima, that is, structures of $\mathrm{OOH}$ adsorbed on $\mathrm{Ti}, \mathrm{Fe}$, and $\mathrm{Co}$ dopants that are metastable. This is in contrast with $\mathrm{V}, \mathrm{Cr}$, and Mn dopants, where no such structures are found.

Only the late TM dopants $\mathrm{Ni}$ and $\mathrm{Cu}$ give $\Delta G_{* \mathrm{OOH}}^{\mathrm{dis}}<0$, eq 20 , which implies a thermodynamically stable adsorbed $\mathrm{OOH}$ species. As discussed above, a strong adsorption of $\mathrm{OH}$ would lead to a substantial overpotential. In the $\mathrm{Ni}$ and $\mathrm{Cu}$ cases, $\Delta \Delta G_{* \mathrm{OH}}>0$, eq 19 , indicating an $\mathrm{OH}$ species that is not adsorbed strongly. In fact, the bonding of $\mathrm{OH}$ to $\mathrm{Ni}$ or $\mathrm{Cu}$ is relatively weak, which implies a minimum overpotential $\eta_{1}=$ $\Delta \Delta G_{* \mathrm{OH}} / e$ resulting from this first reaction step, eq 14 and Figure 2a. Of course, still larger overpotentials may, in principle, follow from the subsequent reaction steps 5-7.

Next, we zoom in on the Gibbs free energy difference that reflects the difference in bonding of $\mathrm{OH}$ and $\mathrm{OOH}$ species to the surface

$$
\Delta G_{23}=\Delta G_{* \mathrm{OOH}}-\Delta G_{* \mathrm{OH}}=\Delta G_{2}+\Delta G_{3}
$$

see eqs 11 and 12 . This quantity thus represents the Gibbs free energy associated with the two reactions 5 and 6 , that is, the two middle steps in the staircases of Figure $2 a$. The calculated values for the TM-doped systems are shown in Figure 4a,b for the AlN and GaN system, respectively.

To avoid the two reaction steps 5 and 6 contributing to an overpotential, $\Delta G_{23}$ should ideally be equal to $2 \Delta G_{0}=2.46 \mathrm{eV}$, see eqs 9 and 14, ${ }^{62}$ for all TM-doped systems, as indicated by the dotted horizontal lines in Figure 4a,b. In general, however, $\Delta G_{23}$ is significantly higher than the ideal value of $2.46 \mathrm{eV}$ and is different for the different TM dopants. For most TM dopants, we find $\Delta G_{23}$ to be between 3.10 and $3.60 \mathrm{eV}$ (Figure $4 \mathrm{a}, \mathrm{b})$, which is consistent with the range found in TM oxides and in TM-doped graphene. ${ }^{27,28,62}$ The minimum overpotential resulting from the two reaction steps 5 and 6 is then

$$
\eta_{23}=\left(\Delta G_{23}-2 \Delta G_{0}\right) /(2 e)
$$

On the basis of the data for all TM-doped systems shown in Figure $4 \mathrm{a}, \mathrm{b}$ and eq $22, \eta_{23}$ mostly ranges between 0.3 and 0.6 $\mathrm{V}$. To decrease this number, one should increase the bonding of $\mathrm{OOH}$ to the $\mathrm{TM}$ with respect to the TM/OH bonding, eq 21. This is observed in the $\mathrm{Ni}$-doped systems, where for $\mathrm{Ni} /$ AlN and $\mathrm{Ni} / \mathrm{GaN}$, we find $\eta_{23}=0.11$ and $0.21 \mathrm{~V}$, respectively. These values are close to a perfect OER catalyst with an overpotential of zero.

The quantity $\eta_{23}$ gives a lower bound to the overpotential in case $\Delta G_{2}=\Delta G_{3}$. If $\Delta G_{2} \neq \Delta G_{3}$, one should also consider the adsorption strength of the $\mathrm{O}$ species with respect to the average of the $\mathrm{OH}$ and $\mathrm{OOH}$ species

$$
\begin{aligned}
\Delta \Delta G_{* \mathrm{O}} & =\Delta G_{* \mathrm{O}}-\frac{1}{2}\left(\Delta G_{* \mathrm{OH}}+\Delta G_{* \mathrm{OOH}}\right) \\
& =\frac{1}{2}\left(\Delta G_{2}-\Delta G_{3}\right)
\end{aligned}
$$

$\Delta \Delta G_{*_{\mathrm{O}}}$ can be derived from Figure 3 as the difference between the Gibbs free energy curve of $* \mathrm{O}$ and the average of the $* \mathrm{OH}$ and $* \mathrm{OOH}$ curves. The minimum overpotential from the two reaction steps 5 and 6 is then

$$
\min \left[\eta_{2}, \eta_{3}\right]=\eta_{23}+\mid \Delta \Delta G_{* \mathrm{O}} \mathrm{l} / e
$$

see eqs 21 and 23 and Figure 4. Ideally, $\Delta \Delta G_{*_{\mathrm{O}}}$ should be as close to zero as possible. Figure $4 \mathrm{c}, \mathrm{d}$ show that $\Delta \Delta G_{*_{\mathrm{O}}}$ starts strongly positive for $\mathrm{Sc}$ and then becomes negative, before becoming positive again for $\mathrm{Cu}$. For most TM dopants, $\left|\Delta \Delta G_{* \mathrm{O}}\right|$ is substantial. Of the late TM dopants, the exceptions are Ni-doped AlN and $\mathrm{GaN}$, where we obtain the relatively small values $\Delta \Delta G_{*_{\mathrm{O}}}=-0.12$ and $-0.16 \mathrm{eV}$, respectively.

In summary, analyzing the Gibbs free energies associated with the bonding of the different adsorbents shows how in particular the Ni-doped systems lead to a low overpotential. First of all, $\mathrm{OH}$ is bonded too strongly to the early TM dopants in the series $\mathrm{Sc}$ to $\mathrm{Fe}$, indicated by $\Delta \Delta G_{* \mathrm{OH}}<0$, eq 19 , which leads to a substantial overpotential. In addition, for the TM dopants in the middle of these series, $\mathrm{V}, \mathrm{Cr}$, and $\mathrm{Mn}$, the $\mathrm{O}$ species is bonded so strongly that $* \mathrm{OOH}$ is unstable with respect to decomposition into $* \mathrm{OH}$ and $* \mathrm{O} . \mathrm{V}, \mathrm{Cr}$, and $\mathrm{Mn}$ dopants should therefore show no activity at all for the OER. For the late TM dopants Co to $\mathrm{Cu}, \mathrm{Ni}$ shows values $\Delta G_{23}$, eq 21 , that are close to the optimal value $2 G_{0}$, whereas the other dopants show higher values. In addition, the value of $\Delta \Delta G_{*_{\mathrm{O}}}$, eq 23, is optimal for the $\mathrm{Ni}$ dopant.

One can try to relate $\Delta G_{* \mathrm{OOH}}$ and $\Delta G_{*_{\mathrm{O}}}$ to $\Delta G_{* \mathrm{OH}}$ by linear scaling relations, as suggested in the literature. ${ }^{28,59,62}$ However, Figure 4 shows that such scaling relations work poorly in the present case.

Electronic Structure of Adsorbed Species. We now focus on the electronic structures of the TM-doped AlN and $\mathrm{GaN}$ layers to see whether the trends found in the binding energies can be explained from the electronic structures. The spin-polarized PDOS of two examples are shown in Figure 5,
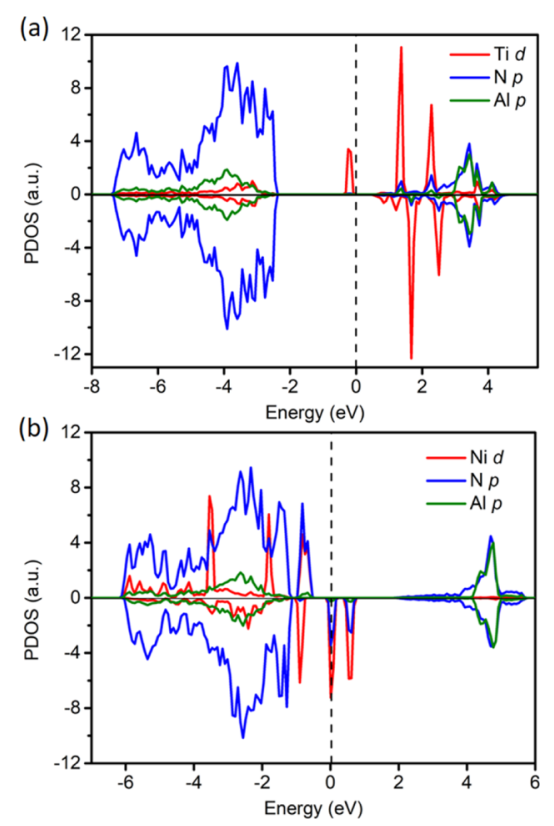

Figure 5. Spin-polarized PDOS of (a) Ti-doped AlN and (b) Nidoped AlN. The highest occupied state is set to $0 \mathrm{eV}$.

an early TM dopant $(\mathrm{Ti})$ and a late $\mathrm{TM}$ dopant $(\mathrm{Ni})$, both in AlN. PDOSs of the full $3 \mathrm{~d}$ TM-doped $\mathrm{XN}$ series, $\mathrm{TM}=\mathrm{Sc}$ to $\mathrm{Zn}, \mathrm{X}=\mathrm{Al}$ and $\mathrm{Ga}$, are given in the Supporting Information in Figures S2 and S3. In addition, orbital-resolved PDOSs for all these cases are given in Figures S4 and S5. It is clear from these figures that the PDOSs of spin-up and spin-down states are different for all TM-doped XN, except for Sc and $\mathrm{Zn}$ dopants. 
Therefore, with the exception of the latter two dopants, TM doping leads to substantial magnetic moments, which to a significant part are carried by the $\mathrm{d}$ states on the TM dopant atoms. Indeed, for the early TM dopants in particular, the PDOS corresponding to the $3 \mathrm{~d}$ states consists of sharp peaks (Figures $\mathrm{S} 2 \mathrm{~b}-\mathrm{d}, \mathrm{S} 3 \mathrm{~b}-\mathrm{d}$ ), signaling that hybridization of these states with the $\mathrm{XN}$ environment is small. Hybridization increases slightly going down the TM series, indicated by some of the peaks attaining a mixed TM-nitrogen character (Figures $\mathrm{S} 2 \mathrm{e}-\mathrm{i}, \mathrm{S} 3 \mathrm{e}-\mathrm{i}$ ) and by a bonding/antibonding splitting in some cases.

Ignoring this hybridization, the nominal charge of a TM substitutional dopant atom in the XN lattice is $3+$. To set up a simple electron counting argument, we assume that all (neutral) TM atoms have a $4 \mathrm{~s}^{2} 3 \mathrm{~d}^{n}$ configuration, and by embedding them in the $\mathrm{XN}$ lattice, two electrons are donated by the TM $4 \mathrm{~s}$ shell and one electron is donated by the $3 \mathrm{~d}$ shell to arrive at a charge $3+$. This would then mean that the TM dopant atom has configuration $4 s^{0} 3 \mathrm{~d}^{n-1}$, where $n$ is the number of $\mathrm{d}$ electrons of the neutral atom. The PDOSs shown in Figures 5, S4b and S4h are indeed consistent with $\mathrm{d}^{1}$ for the Ti dopant, and with $\mathrm{d}^{7}$ for the $\mathrm{Ni}$ dopant. In fact, most of the PDOSs of the Supporting Information Figures S2-S5 comply with the TM configuration $\mathrm{d}^{n-1}$ and thus with a nominal charge of $3+$. The exceptions are the late TM dopants $\mathrm{Cu}$ and $\mathrm{Zn}$, which have configurations $\mathrm{d}^{n}$, that is, $\mathrm{d}^{9}$ and $\mathrm{d}^{10}$, respectively (Figures S4i,j and S5i,j), indicating a nominal charge of $2+$.

Most prominent in Figure 5 is that the $\mathrm{d}$ states of $\mathrm{Ti}$ are in energy more than $2 \mathrm{eV}$ above the valence band of AlN, whereas the $\mathrm{d}$ states of $\mathrm{Ni}$ largely overlap with the valence band. One therefore expects the $\mathrm{d}^{1}$ state of $\mathrm{Ti}$ to be more reactive toward adsorption of an electron-accepting $\mathrm{OH}$ species than either the AlN substrate or the $\mathrm{Ni} d$ states. The $\mathrm{d}$ states go down in energy along the TM series from $\mathrm{Ti}$ to $\mathrm{Zn}$, see Figures S2 and S3; hence, the reactivity should go down. Indeed, this can be seen as an increase in $\Delta G_{* \mathrm{OH}}$ along the TM series in Figure 3.

Adsorption of the $\mathrm{O}$ species requires two electrons from the substrate instead of only one, as in the case of $\mathrm{OH}$ species. One expects adsorption to be strongest for a TM dopant with $\mathrm{d}^{2}$ configuration, which is the TM dopant $\mathrm{V}$. The $\Delta G_{*_{\mathrm{O}}}$ curve in Figure 3 shows that this is indeed the case.

To clarify why doping by $\mathrm{Ni}$ is particularly advantageous for obtaining a low overpotential, we consider the spin state of the TM-doped XN layers. If the TM d-levels were purely atomic, then Hund's (first) rule would predict a high-spin state for all dopant atoms. On the basis of the electron-counting argument outlined above, Hund's rule would give for the 3+ TM dopants Sc to Fe a spin $(n-1) \frac{1}{2}$, for the TM dopants Co and $\mathrm{Ni}$ a spin $(10-n+1) \frac{1}{2}=\frac{4}{2}$ and $\frac{3}{2}$, respectively, and for the $2+\mathrm{TM}$ dopants $\mathrm{Cu}$ and $\mathrm{Zn}$ a spin $\frac{1}{2}$ and 0 , respectively. Hybridization between the TM and XN states gives a ligand field that lifts the degeneracy of the d-levels. For instance, it can be observed in Figure 5a that the peaks of the spin-up $\mathrm{d}$ states of $\mathrm{Ti}$ are distributed over a range from -0.2 to $2.3 \mathrm{eV}$, which illustrates that this splitting is easily of the order of several eV's. If ligandfield splitting would be the dominant energy scale, this would force the TM-doped systems into low-spin states.

The calculated total magnetic moments of the TM dopants are listed in Table 1. All TM dopant atoms are found in their
Table 1. Calculated Total Magnetic Moments (in $\mu_{\mathrm{B}}$ per Supercell) of TM-Doped XN, X $=\mathrm{Al}$ and $\mathrm{Ga}^{a}$

\begin{tabular}{lcccccccccc}
\multicolumn{1}{c}{ system } & $\mathrm{Sc}$ & $\mathrm{Ti}$ & $\mathrm{V}$ & $\mathrm{Cr}$ & $\mathrm{Mn}$ & $\mathrm{Fe}$ & $\mathrm{Co}$ & $\mathrm{Ni}$ & $\mathrm{Cu}$ & $\mathrm{Zn}$ \\
nothing adsorbed & 0 & 1 & 2 & 3 & 4 & 5 & 4 & 3 & 1 & 0 \\
OH adsorbed & 0 & 0 & 1 & 2 & 3 & 4 & 5 & 4 & 1 & $/$ \\
O adsorbed & 0 & 0 & 0 & 1 & 2 & 3 & 0 & 1 & 1 & $/$ \\
OOH adsorbed & 0 & 0 & $/$ & $/$ & $/$ & 4 & 5 & 2 & 1 & $/$
\end{tabular}

a/ means that the intermediates do not adsorb stably or metastably on the dopants.

high-spin state predicted by Hund's rule, see the first line in Table 1. It demonstrates that the energy scale associated with Hund's rule still prevails over the ligand-field splitting. The magnetic moments of the late TM dopants are not completely localized on the TM atoms because of the increased hybridization with the $\mathrm{XN}$ lattice. The components of the magnetic moments projected on the TM site are given in Table S3 in the Supporting Information.

A similar analysis of the d-level spectrum and the associated spin states can be performed with the $\mathrm{OH}, \mathrm{O}$, or $\mathrm{OOH}$ species adsorbed on the TM dopant atom. The calculated orbitalresolved PDOSs are given in the Supporting Information, Figures S6-S8, and the calculated total magnetic moments are given in Table 1. Comparing the first two rows in Table 1, one observes that the entries of the second row are shifted one element to the right, as compared to the first row. Therefore, it seems that adsorption of $\mathrm{OH}$ decreases the number of electrons on the TM dopant by 1 , thus changing its configuration to $\mathrm{d}^{n-2}$, while the systems with $\mathrm{OH}$ adsorbed still obey Hund's rule, and are found in their high-spin state. Exceptions are $\mathrm{Cu}$, which remains in a $\mathrm{d}^{9}$ configuration even with $\mathrm{OH}$ adsorbed, and the trivial case Sc, which remains in a $\mathrm{d}^{0}$ configuration.

Applying the same reasoning to an adsorbed $\mathrm{O}$ atom, one may expect that adsorption of $\mathrm{O}$ decreases the number of electrons on the TM dopant by 2, thus changing its configuration to $\mathrm{d}^{n-3}$. If Hund's rule applies, resulting in high-spin states, then the third row in Table 1 could be obtained from the second row by again shifting it one element to the right. This is indeed the case for all TM dopants up to $\mathrm{Fe}$. As before, $\mathrm{Cu}$ remains in a $\mathrm{d}^{9}$ configuration even with $\mathrm{O}$ adsorbed. Remarkably, for $\mathrm{O}$ adsorption on the late TM dopants $\mathrm{Co}$ and $\mathrm{Ni}$, the total magnetic moments for $\mathrm{O}-\mathrm{Co} /$ $\mathrm{XN}$ and $\mathrm{O}-\mathrm{Ni} / \mathrm{XN}$ are 0 and $1 \mu_{\mathrm{B}}$, respectively, see Table 1 and Figure 6, implying that the preferred configuration is the low-spin state.

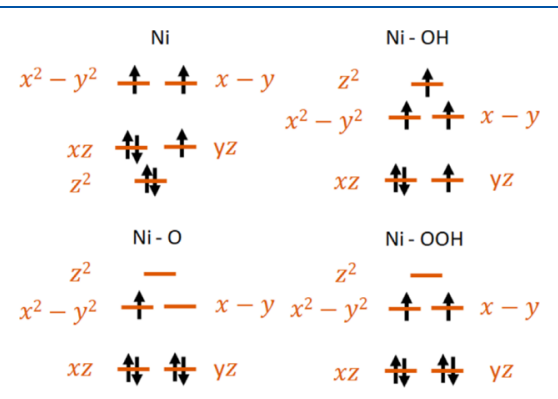

Figure 6. Schematic ligand-field splitting of Ni d-levels for Ni-doped $\mathrm{XN}, \mathrm{X}=\mathrm{Al}$ and $\mathrm{Ga}$. The pristine and $\mathrm{OH}$-adsorbed systems are in a high-spin state, whereas the $\mathrm{O}$-adsorbed and $\mathrm{OOH}$-adsorbed systems are in a low-spin state, see Table 1. 
The total magnetic moment and the energy difference $\Delta E(* \mathrm{O})$ between the high-spin and the low-spin states of $\mathrm{O}-$ $\mathrm{Co} / \mathrm{XN}$ and $\mathrm{O}-\mathrm{Ni} / \mathrm{XN}$ are listed in Table S4. The high-spin state of these systems is $0.5-0.6 \mathrm{eV}$ higher in energy than the low-spin state (with the exception of $\mathrm{O}-\mathrm{Ni} / \mathrm{AlN}$, where the high-spin state does not give a stable adsorption of $\mathrm{O}$ on $\mathrm{Ni}$ ). Assuming that both the $\mathrm{OH}$ and $\mathrm{OOH}$ species adsorb in a high-spin state, as is the case for most TM dopants, then stabilization of the low-spin state of an adsorbed $\mathrm{O}$ species results in a $\Delta \Delta G_{*_{0} \mathrm{O}}$, eq 23 , that is strongly negative, which leads to a substantial overpotential, see eq 24 and Figure 2. Indeed, it can be observed in Figure 4c,d that this is the case for $\Delta \Delta G_{*_{\mathrm{O}}}$ of Co-doped AlN and GaN. Remarkably, the stable low-spin state of the $\mathrm{O}-\mathrm{Ni} / \mathrm{XN}$ systems does not cause a similarly negative $\Delta \Delta G_{*_{\mathrm{O}}}$ and a high overpotential. This has to do with the stable spin state of an adsorbed $\mathrm{OOH}$ species.

If adsorption of $\mathrm{OOH}$ is similar to that of $\mathrm{OH}$, then the electron count gives a $\mathrm{d}^{n-2}$ configuration for both cases, and Hund's rule should give an identical high-spin state for both cases. Judging from the magnetic moments listed in Table 1, this is indeed the case for most of the TM dopants where $\mathrm{OOH}$ can be stably adsorbed. The notable exception is Ni. Here, the adsorbed $\mathrm{OOH}$ remains in a low-spin state, similar to adsorbed $\mathrm{O}$, and does not switch to a high-spin state similar to adsorbed $\mathrm{OH}$, as it does for all other TM dopants. Figure 6 visualizes the assembly of spin states that is unique for the $\mathrm{Ni}$ dopant. As the low-spin states of both the adsorbed $\mathrm{O}$ and the $\mathrm{OOH}$ species on $\mathrm{Ni}$ are stabilized, this leads to a decrease of $\Delta G_{23}$ (eq 21), as well as $\left|\Delta \Delta G_{*_{\mathrm{O}}}\right|$ (eq 23), see Figure 4, which then yields a low overpotential.

\section{SUMMARY}

In summary, we have investigated the OER of water splitting on first-row TM-doped AlN and GaN 2D monolayers by DFT calculations. The binding strength of $\mathrm{OH}$ or $\mathrm{O}$, overpotential, overpotential-determining reaction steps, and spin states of *OOH of the TM-doped systems are summarized in Figure 7. We find that the Ni-doped AlN and GaN monolayers single out as most favorable for the OER, as they lead to small calculated OER overpotentials of 0.38 and $0.37 \mathrm{~V}$, respectively.

Early TM dopants are not suited for an efficient OER because in the first reaction step of the OER, they bind the $\mathrm{OH}$ species too strongly. In fact, $\mathrm{V}, \mathrm{Cr}$, and $\mathrm{Mn}$ dopants should show no activity for the OER at all because additionally in the second OER step, they bind the O species so strongly that the

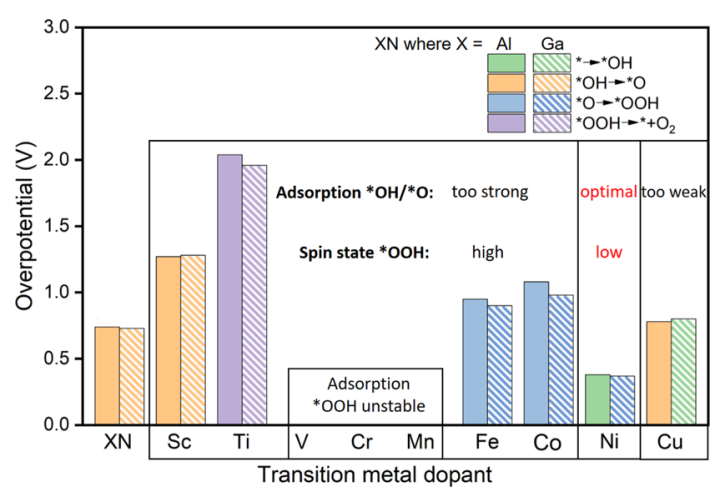

Figure 7. Binding strength of $\mathrm{OH}$ or $\mathrm{O}$, overpotential, overpotentialdetermining reaction steps and spin states of $* \mathrm{OOH}$ of the TM-doped systems. third step, conversion to $\mathrm{OOH}$, becomes impossible. The latter becomes feasible for late TM dopants, but for $\mathrm{Fe}$ and $\mathrm{Co}$, it is still energetically costly because of the strong binding of the $\mathrm{O}$ species. Elements at the end of the TM series, $\mathrm{Cu}$ and $\mathrm{Zn}$, show little or no activity. They bind adsorbants weakly, and their d-shells do not participate in this bonding.

$\mathrm{Ni}$ is unique as a dopant in these systems, as all four reaction steps of the OER are relatively close to their optimal values, meaning that the adsorption energies of the three intermediate-adsorbed species, $\mathrm{OH}, \mathrm{O}$, and $\mathrm{OOH}$, are close to optimal. For instance, the Gibbs free energy difference between $\mathrm{OH}$ and $\mathrm{OOH}$ adsorbed on the $\mathrm{Ni}$ dopant is $\sim 2.7 \mathrm{eV}$, which is significantly lower than $\sim 3.3 \mathrm{eV}$ found for adsorption on the other dopants. The latter value is close to that found more generally for other compounds. In contrast, the value for $\mathrm{Ni}$ is rather close to the ideal value of $2.46 \mathrm{eV}$ for a perfect catalyst.

The numbers correlate with the spin states of the TM dopants. In most cases, the high-spin state is preferred both for the pristine TM-doped $\mathrm{AlN}$ and $\mathrm{GaN}$, as well as for all intermediate species involved in the OER, that is, $\mathrm{OH}, \mathrm{O}$, and $\mathrm{OOH}$ adsorbed on the TM dopant. However, for the $\mathrm{Ni}$ dopant, the low-spin state is stabilized both for the adsorbed $\mathrm{O}$, as well as for the adsorbed $\mathrm{OOH}$ species (whereas the highspin state is most stable for adsorbed $\mathrm{OH}$ and for the pristine dopant). This stabilization leads to a low overpotential in the $\mathrm{Ni}$-doped AlN and GaN. Such a change in spin state adds a degree of freedom to optimize the overpotential required for the OER.

\section{ASSOCIATED CONTENT}

\section{Supporting Information}

The Supporting Information is available free of charge on the ACS Publications website at DOI: 10.1021/acs.jpcc.9b06704.

Zero-point energy and entropic correction; optimized structures of TM-doped AlN and $\mathrm{GaN}$ with/without adsorbants; Gibbs free energies; spin-polarized PDOS of TM-doped AlN and GaN; spin-polarized PDOS of TMdoped $\mathrm{AlN}$ and $\mathrm{GaN}$ with adsorbed $\mathrm{OH}, \mathrm{O}$, and $\mathrm{OOH}$; magnetic moments of TM dopant ions in AlN; high-spin versus low-spin states; GGA $+U$ calculations for $\mathrm{Co} / \mathrm{XN}$ and $\mathrm{Ni} / \mathrm{XN}$; and comparison of the results with those of the standard GGA calculations (PDF)

\section{AUTHOR INFORMATION}

\section{Corresponding Author}

*E-mail: A.Bieberle@differ.nl.

ORCID $\odot$

Qiuhua Liang: 0000-0002-5436-5203

Xueqing Zhang: 0000-0002-7310-3858

Anja Bieberle-Hütter: 0000-0001-8794-9312

\section{Notes}

The authors declare no competing financial interest.

\section{ACKNOWLEDGMENTS}

Q.L. acknowledges funding from the China Scholarship Council (CSC) (no. 201708450082). X.Z. and A.B.-H. acknowledge the financial support from NWO (FOM program no. 147 " $\mathrm{CO}_{2}$ neutral fuels") and from M-ERA.NET (project "MuMo4PEC" with project number M-ERA.NET 4089). Supercomputing facilities of the Dutch national super- 
computers SURFsara/Lisa and Cartesius are acknowledged. Vivek Sinha is acknowledged for fruitful discussions.

\section{REFERENCES}

(1) Tahir, M.; Pan, L.; Idrees, F.; Zhang, X.; Wang, L.; Zou, J.-J.; Wang, Z. L. Electrocatalytic oxygen evolution reaction for energy conversion and storage: A comprehensive review. Nano Energy 2017, 37, 136-157.

(2) Zhang, W.; Zhou, K. Ultrathin Two-Dimensional Nanostructured Materials for Highly Efficient Water Oxidation. Small 2017, 13, 1700806.

(3) Suen, N.-T.; Hung, S.-F.; Quan, Q.; Zhang, N.; Xu, Y.-J.; Chen, H. M. Electrocatalysis for the oxygen evolution reaction: recent development and future perspectives. Chem. Soc. Rev. 2017, 46, 337365.

(4) Gao, G.; Bottle, S.; Du, A. Understanding the activity and selectivity of single atom catalysts for hydrogen and oxygen evolution via ab initial study. Catal. Sci. Technol. 2018, 8, 996-1001.

(5) Zhang, X.; Bieberle-Hütter, A. Modeling and simulations in photoelectrochemical water oxidation: from single level to multiscale modeling. ChemSusChem 2016, 9, 1223-1242.

(6) Casalongue, H. G. S.; Ng, M. L.; Kaya, S.; Friebel, D.; Ogasawara, H.; Nilsson, A. In situ observation of surface species on iridium oxide nanoparticles during the oxygen evolution reaction. Angew. Chem., Int. Ed. 2014, 53, 7169-7172.

(7) Paoli, E. A.; Masini, F.; Frydendal, R.; Deiana, D.; Schlaup, C.; Malizia, M.; Hansen, T. W.; Horch, S.; Stephens, I. E. L.; Chorkendorff, I. Oxygen evolution on well-characterized massselected $\mathrm{Ru}$ and $\mathrm{RuO} 2$ nanoparticles. Chem. Sci. 2015, 6, 190-196.

(8) Zhang, X.; Cao, C.; Bieberle-Hütter, A. Orientation sensitivity of oxygen evolution reaction on hematite. J. Phys. Chem. C 2016, 120, 28694-28700.

(9) Zhang, X.; Klaver, P.; van Santen, R.; Van De Sanden, M. C. M.; Bieberle-Hütter, A. Oxygen evolution at hematite surfaces: the impact of structure and oxygen vacancies on lowering the overpotential. $J$. Phys. Chem. C 2016, 120, 18201-18208.

(10) Dahan, M. H.; Caspary Toroker, M. Water oxidation catalysis with $\mathrm{Fe} 2 \mathrm{O} 3$ constrained at the nanoscale. J. Phys. Chem. C 2017, 121, 6120-6125.

(11) Sivula, K.; Le Formal, F.; Grätzel, M. Solar water splitting: progress using hematite $(\alpha$-Fe2O3) photoelectrodes. ChemSusChem 2011, 4, 432-449.

(12) In, S.; Orlov, A.; Berg, R.; García, F.; Pedrosa-Jimenez, S.; Tikhov, M. S.; Wright, D. S.; Lambert, R. M. Effective visible lightactivated B-doped and $\mathrm{B}, \mathrm{N}$-codoped $\mathrm{TiO} 2$ photocatalysts. J. Am. Chem. Soc. 2007, 129, 13790-13791.

(13) Ikuma, Y.; Bessho, H. Effect of Pt concentration on the production of hydrogen by a $\mathrm{TiO} 2$ photocatalyst. Int. J. Hydrogen Energy 2007, 32, 2689-2692.

(14) Kishore, R.; Cao, X.; Zhang, X.; Bieberle-Hütter, A. Electrochemical water oxidation on WO3 surfaces: A density functional theory study. Catal. Today 2019, 321-322, 94-99.

(15) Zhao, Y.; Balasubramanyam, S.; Sinha, R.; Lavrijsen, R.; Verheijen, M. A.; Bol, A. A.; Bieberle-Hütter, A. Physical and Chemical Defects in WO3 Thin Films and Their Impact on Photoelectrochemical Water Splitting. ACS Appl. Energy Mater. 2018, 1, 5887-5895.

(16) Hamdani, M.; Singh, R.; Chartier, P. Co3O4 and Co-based spinel oxides bifunctional oxygen electrodes. Int. J. Electrochem. Sci. 2010, 5, 556-577.

(17) Pham, H. H.; Cheng, M.-J.; Frei, H.; Wang, L.-W. Surface proton hopping and fast-kinetics pathway of water oxidation on Co3O4 (001) surface. ACS Catal. 2016, 6, 5610-5617.

(18) Huynh, M.; Shi, C.; Billinge, S. J. L.; Nocera, D. G. Nature of activated manganese oxide for oxygen evolution. J. Am. Chem. Soc. 2015, 137, 14887-14904.

(19) Tripkovic, V.; Hansen, H. A.; Vegge, T. Computational Screening of Doped $\alpha-\mathrm{MnO} 2$ Catalysts for the Oxygen Evolution Reaction. ChemSusChem 2018, 11, 629-637.
(20) Osgood, H.; Devaguptapu, S. V.; Xu, H.; Cho, J.; Wu, G. Transition metal (Fe, $\mathrm{Co}, \mathrm{Ni}$, and $\mathrm{Mn}$ ) oxides for oxygen reduction and evolution bifunctional catalysts in alkaline media. Nano Today 2016, 11, 601-625.

(21) Xu, L.; Jiang, Q.; Xiao, Z.; Li, X.; Huo, J.; Wang, S.; Dai, L. Plasma-Engraved $\mathrm{Co} 3 \mathrm{O} 4$ Nanosheets with Oxygen Vacancies and High Surface Area for the Oxygen Evolution Reaction. Angew. Chem., Int. Ed. 2016, 55, 5277-5281.

(22) Zhao, Q.; Yan, Z.; Chen, C.; Chen, J. Spinels: controlled preparation, oxygen reduction/evolution reaction application, and beyond. Chem. Rev. 2017, 117, 10121-10211.

(23) Kalantar-zadeh, K.; Ou, J. Z.; Daeneke, T.; Mitchell, A.; Sasaki, T.; Fuhrer, M. S. Two dimensional and layered transition metal oxides. Appl. Mater. Today 2016, 5, 73-89.

(24) Ida, S.; Ishihara, T. Recent progress in two-dimensional oxide photocatalysts for water splitting. J. Phys. Chem. Lett. 2014, 5, 25332542.

(25) Novoselov, K. S.; Geim, A. K.; Morozov, S. V.; Jiang, D.; Zhang, Y.; Dubonos, S. V.; Grigorieva, I. V.; Firsov, A. A. Electric field effect in atomically thin carbon films. science 2004, 306, 666-669.

(26) Zhou, S.; Liu, N.; Wang, Z.; Zhao, J. Nitrogen-doped graphene on transition metal substrates as efficient bifunctional catalysts for oxygen reduction and oxygen evolution reactions. ACS Appl. Mater. Interfaces 2017, 9, 22578-22587.

(27) Zhang, X.; Yang, Z.; Lu, Z.; Wang, W. Bifunctional CoNx embedded graphene electrocatalysts for OER and ORR: a theoretical evaluation. Carbon 2018, 130, 112-119.

(28) Calle-Vallejo, F.; Martínez, J. I.; Rossmeisl, J. Density functional studies of functionalized graphitic materials with late transition metals for oxygen reduction reactions. Phys. Chem. Chem. Phys. 2011, 13, $15639-15643$.

(29) Zhou, Y.; Gao, G.; Li, Y.; Chu, W.; Wang, L.-W. Transitionmetal single atoms in nitrogen-doped graphene as efficient active centers for water splitting: A theoretical study. Phys. Chem. Chem. Phys. 2019, 21, 3024-3032.

(30) Li, X.; Zhong, W.; Cui, P.; Li, J.; Jiang, J. Design of efficient catalysts with double transition metal atoms on $\mathrm{C} 2 \mathrm{~N}$ layer. J. Phys. Chem. Lett. 2016, 7, 1750-1755.

(31) Zheng, Y.; Jiao, Y.; Zhu, Y.; Cai, Q.; Vasileff, A.; Li, L. H.; Han, Y.; Chen, Y.; Qiao, S.-Z. Molecule-level g-C3N4 coordinated transition metals as a new class of electrocatalysts for oxygen electrode reactions. J. Am. Chem. Soc. 2017, 139, 3336-3339.

(32) Qin, Z.; Qin, G.; Zuo, X.; Xiong, Z.; Hu, M. Orbitally driven low thermal conductivity of monolayer gallium nitride $(\mathrm{GaN})$ with planar honeycomb structure: a comparative study. Nanoscale 2017, 9, 4295-4309.

(33) Şahin, H.; Cahangirov, S.; Topsakal, M.; Bekaroglu, E.; Akturk, E.; Senger, R. T.; Ciraci, S. Monolayer honeycomb structures of group-IV elements and III-V binary compounds: First-principles calculations. Phys. Rev. B: Condens. Matter Mater. Phys. 2009, 80, 155453 .

(34) Kadioglu, Y.; Ersan, F.; Kecik, D.; Aktürk, O. Ü.; Aktürk, E.; Ciraci, S. Chemical and substitutional doping, and anti-site and vacancy formation in monolayer AlN and GaN. Phys. Chem. Chem. Phys. 2018, 20, 16077-16091.

(35) Tsipas, P.; Kassavetis, S.; Tsoutsou, D.; Xenogiannopoulou, E.; Golias, E.; Giamini, S. A.; Grazianetti, C.; Chiappe, D.; Molle, A.; Fanciulli, M.; Dimoulas, A. Evidence for graphite-like hexagonal AlN nanosheets epitaxially grown on single crystal Ag (111). Appl. Phys. Lett. 2013, 103, 251605.

(36) Al Balushi, Z. Y.; Wang, K.; Ghosh, R. K.; Vilá, R. A.; Eichfeld, S. M.; Caldwell, J. D.; Qin, X.; Lin, Y.-C.; DeSario, P. A.; Stone, G.; Subramanian, S.; Paul, D. F.; Wallace, R. M.; Datta, S.; Redwing, J. M.; Robinson, J. A. Two-dimensional gallium nitride realized via graphene encapsulation. Nat. Mater. 2016, 15, 1166-1171.

(37) Zhang, H.; Zhang, Y.-N.; Liu, H.; Liu, L.-M. Novel heterostructures by stacking layered molybdenum disulfides and nitrides for solar energy conversion. J. Mater. Chem. A 2014, 2, $15389-15395$. 
(38) Liao, J.; Sa, B.; Zhou, J.; Ahuja, R.; Sun, Z. Design of highefficiency visible-light photocatalysts for water splitting: MoS2/AlN (GaN) heterostructures. J. Phys. Chem. C 2014, 118, 17594-17599.

(39) Guo, J.; Zhou, Z.; Wang, T.; Lu, Z.; Yang, Z.; Liu, C. Electronic structure and optical properties for blue phosphorene/graphene-like GaN van der Waals heterostructures. Curr. Appl. Phys. 2017, 17, $1714-1720$

(40) Bonanni, A. Ferromagnetic nitride-based semiconductors doped with transition metals and rare earths. Semicond. Sci. Technol. 2007, 22, R41-R56.

(41) González-Hernández, R.; López-Pérez, W.; Guadalupe Moreno-Armenta, M.; Arbey Rodríguez M, J. Adsorption and diffusion of $3 \mathrm{~d}$ transition metal atoms on the $\mathrm{GaN}$ (0001) surface. J. Appl. Phys. 2011, 110, 083712.

(42) Shakil, M.; Hussain, A.; Zafar, M.; Ahmad, S.; Khan, M. I.; Masood, M. K.; Majid, A. Ferromagnetism in GaN doped with transition metals and rare-earth elements: A review. Chin. J. Phys. 2018, 56, 1570-1577.

(43) Gao, G.; Waclawik, E. R.; Du, A. Computational screening of two-dimensional coordination polymers as efficient catalysts for oxygen evolution and reduction reaction. J. Catal. 2017, 352, 579585 .

(44) Burke, M. S.; Enman, L. J.; Batchellor, A. S.; Zou, S.; Boettcher, $S$. W. Oxygen evolution reaction electrocatalysis on transition metal oxides and (oxy) hydroxides: activity trends and design principles. Chem. Mater. 2015, 27, 7549-7558.

(45) Zaffran, J.; Toroker, M. C. Designing efficient doped NiOOH catalysts for water splitting with first principles calculations. ChemistrySelect 2016, 1, 911-916.

(46) Liao, P.; Keith, J. A.; Carter, E. A. Water oxidation on pure and doped hematite (0001) surfaces: Prediction of $\mathrm{Co}$ and $\mathrm{Ni}$ as effective dopants for electrocatalysis. J. Am. Chem. Soc. 2012, 134, 1329613309.

(47) Stevens, M. B.; Enman, L. J.; Korkus, E. H.; Zaffran, J.; Trang, C. D.; Asbury, J.; Kast, M. G.; Toroker, M. C.; Boettcher, S. W. Ternary Ni-Co-Fe oxyhydroxide oxygen evolution catalysts: Intrinsic activity trends, electrical conductivity, and electronic band structure. Nano Res. 2019, 12, 2288.

(48) Blöchl, P. E. Projector augmented-wave method. Phys. Rev. B: Condens. Matter Mater. Phys. 1994, 50, 17953.

(49) Kresse, G.; Joubert, D. From ultrasoft pseudopotentials to the projector augmented-wave method. Phys. Rev. B: Condens. Matter Mater. Phys. 1999, 59, 1758.

(50) Kresse, G.; Furthmüller, J. Efficient iterative schemes for ab initio total-energy calculations using a plane-wave basis set. Phys. Rev. B: Condens. Matter Mater. Phys. 1996, 54, 11169.

(51) Perdew, J. P.; Burke, K.; Ernzerhof, M. Generalized gradient approximation made simple. Phys. Rev. Lett. 1996, 77, 3865.

(52) Dudarev, S. L.; Botton, G. A.; Savrasov, S. Y.; Humphreys, C. J.; Sutton, A. P. Electron-energy-loss spectra and the structural stability of nickel oxide: An LSDA+ U study. Phys. Rev. B: Condens. Matter Mater. Phys. 1998, 57, 1505.

(53) Neugebauer, J.; Scheffler, M. Adsorbate-substrate and adsorbate-adsorbate interactions of $\mathrm{Na}$ and $\mathrm{K}$ adlayers on $\mathrm{Al}$ (111). Phys. Rev. B: Condens. Matter Mater. Phys. 1992, 46, 16067.

(54) Monkhorst, H. J.; Pack, J. D. Special points for Brillouin-zone integrations. Phys. Rev. B: Solid State 1976, 13, 5188.

(55) Grimme, S. Semiempirical GGA-type density functional constructed with a long-range dispersion correction. J. Comput. Chem. 2006, 27, 1787-1799.

(56) van Setten, M. J.; de Wijs, G. A.; Brocks, G. First-principles calculations of the crystal structure, electronic structure, and thermodynamic stability of $\mathrm{Be}(\mathrm{BH} 4) 2$. Phys. Rev. B: Condens. Matter Mater. Phys. 2008, 77, 165115.

(57) Asthagiri, A.; Janik, M. J. Computational Catalysis; Royal Society of Chemistry: Cambridge, 2013.

(58) Nørskov, J. K.; Rossmeisl, J.; Logadottir, A.; Lindqvist, L.; Kitchin, J. R.; Bligaard, T.; Jonsson, H. Origin of the overpotential for oxygen reduction at a fuel-cell cathode. J. Phys. Chem. B 2004, 108, 17886-17892.

(59) Rossmeisl, J.; Qu, Z.-W.; Zhu, H.; Kroes, G.-J.; Nørskov, J. K. Electrolysis of water on oxide surfaces. J. Electroanal. Chem. 2007, 607, $83-89$.

(60) Dickens, C. F.; Kirk, C.; Nørskov, J. K. Insights into the Electrochemical Oxygen Evolution Reaction with ab Initio Calculations and Microkinetic Modeling: Beyond the Limiting Potential Volcano. J. Phys. Chem. C 2019, 123, 18960-18977.

(61) Kment, S.; Schmuki, P.; Hubicka, Z.; Machala, L.; Kirchgeorg, R.; Liu, N.; Wang, L.; Lee, K.; Olejnicek, J.; Cada, M.; Gregora, I.; Zboril, R. Photoanodes with fully controllable texture: the enhanced water splitting efficiency of thin hematite films exhibiting solely (110) crystal orientation. ACS Nano 2015, 9, 7113-7123.

(62) Man, I. C.; Su, H. Y.; Calle-Vallejo, F.; Hansen, H. A.; Martínez, J. I.; Inoglu, N. G.; Kitchin, J.; Jaramillo, T. F.; Nørskov, J. K.; Rossmeisl, J. Universality in oxygen evolution electrocatalysis on oxide surfaces. ChemCatChem 2011, 3, 1159-1165. 